\title{
Research on Solar Resource Evaluation Method Based on Mathematical Statistics
}

\author{
Mingzhi Zhao ${ }^{\mathrm{a}}$, Xiaobo Kang ${ }^{\mathrm{b}}$, Xu Zhang ${ }^{\mathrm{c}}$, Lulu Zou ${ }^{\mathrm{c}}$ \\ Inner Mongol University of Technology, Hohhot 010051, China

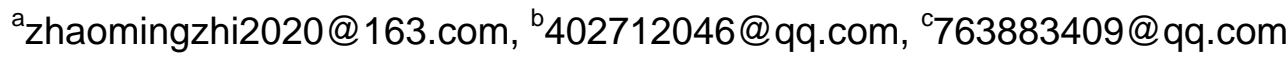

Keywords: mathematical statistics; resource evaluation; solar energy; principal component analysis.

\begin{abstract}
According to the satellite data provided by the US Renewable Energy Laboratory, the datum of solar resources 25 typical cities in China for 29 years were analysed by method of principal component analysis and the whole evaluation of this kind of energy was summarized. The indicators for evaluation of solar energy resources, including richness, stability, utilization value and mean of effective sunshine duration, are incorporated into three main parameters. And the score of principal component is considered as the main factor of the resource evaluation. The evaluation and prediction of solar energy in a region are efficient and accurate by this method, which provide guidance for utilization and development of solar energy.
\end{abstract}

\section{Introduction}

Solar energy is explored more widely due to its "infinity" of reserves, the universality of existence, the cleanliness of development and utilization, and gradually revealed positive economic performance. Exploring solar resources is an effective solution to like energy shortages, environmental pollution, greenhouse effect and other issues brought by using conventional energy sources, especially fossil energy sources. Therefore, scientific and rational assessment of solar energy resources is worthy of attention. An accurate and detailed resource assessment can provide a comprehensive acknowledgement for energy resources and a standard for choosing effective energy for some regions. This not only achieves the good utilization of solar energy, but also cuts the cost of development and boosts local economic development.

Nowadays, some scholars have done the following researches: Han et al.[1] evaluates four indicators of solar energy: the richness, the practical value, the stability, and the best period through the measured data in order to illustrate Ningxia Solar energy resources. Yuan et al.[2] review the main research results of solar energy resources assessment in China from the aspects of solar energy resource estimation, utilization value, stability degree and daily optimal utilizing time. Zhu et al.[3] and some other scholars using the data of six radial station in Gansu, analyze the solar energy distribution in Gansu Province by climatological methods. Liang et al.[4] researches changes of solar energy resources at different time scales and analyzes the diurnal variation of total solar radiation for 30 days under the typical weather conditions of sunny, cloudy and rainy days using solar radiation diurnal variation analysis reflecting the stability of solar energy resources in 1 day. Many scholars use meteorological station observation to assess the solar energy resources of some provinces and cities [5-11]. The research done by the above scholars is to evaluate the solar energy resources in a certain area or to analyze the temporal and spatial distribution of solar energy resources. The solar energy resource stability, utilization value, abundance degree and daily optimum utilization time were respectively considered as main parameters in the previous works. However, the comprehensive effects of these parameters on evaluation of solar energy resources were not given nearly enough attention.

In this paper, the solar energy is evaluated by four parameters: richness, utilization value, stability and mean effective sunshine duration. Through using mathematical analysis, criteria for overall evaluation will be provided. The process will show that the practical value is similar to the average effective hours of sunshine. So the four evaluation indicators are reduced to three proving validity of the method. 


\section{Criteria Analysis and evaluation}

The data used in this paper were provided by the Renewable Energy Laboratory of the United States for a total of 29 years from 1973-2001. Due to the differences in measuring instruments, the total solar radiation data prior to 1 January 1981 is required to be multiplied by a factor of 1.022[12] to ensure comparability of the data.

\subsection{Richness}

According to the richness classification in the Solar Energy Resource Assessment Method (QX / $\mathrm{T}$ 89-2008), which was promulgated and implemented on August 1, 2008, the solar energy abundance in different regions can be classified in a general way. The classification level is shown in Table 1.

Table 1 Degree grade of abundance about solar resource

\begin{tabular}{|l|l|}
\hline total annual radiation $\left(\mathrm{kW} \cdot \mathrm{h} /\left(\mathrm{m}^{2} \cdot \mathrm{a}\right)\right)$ & Richness of resources \\
\hline$\geq 1740$ & Resource very rich \\
\hline $1400 \sim 1739$ & Resource-rich \\
\hline $1160 \sim 1399$ & Resource-poor \\
\hline$<1159$ & Resource very poor \\
\hline
\end{tabular}

Average of surface solar total radiation in 25 cities for 29 years is shown in Table 2. According to the statistical data in Table 2, the top three total annual radiations are Mangya $1783.146 \mathrm{kWh} / \mathrm{m} 2$, Pari $1740.845 \mathrm{kWh} / \mathrm{m} 2$, Delingha $1701.517 \mathrm{kWh} / \mathrm{m} 2$. The total radiation of Mangya and Pari is greater than $1740 \mathrm{kWh} / \mathrm{m} 2$ belonging to resource very rich areas; and Delingha's total radiation is between $1400 \sim 1740 \mathrm{kWh} / \mathrm{m} 2$, which is relatively resource-rich areas. The city with the smallest total annual radiation -- 1272.372kWh / m2 is Guiyang, between $1160 \sim 1400 \mathrm{kWh} / \mathrm{m} 2$, which belongs to the region with resource-poor areas. Among the 25 cities surveyed, there are two cities that are very rich in solar energy resources, accounting for $8 \%$ of the total solar energy resources. There are 19 cities with rich solar energy resources, accounting for $76 \%$. The four cities belongs poor-resource areas accounting for $16 \%$.

\subsection{Utilization value}

The utilization value is always reflected by the number of days with sunshine hours greater than 6[13]. The sunshine hours specified in the meteorological industry standard are defined as the sum of hours of solar radiation reaching or exceeding 120 (W/ m2), with one decimal, in unit of hours. If the number of sunshine hours in a day are less than 6 , then that solar energy is not valuable. The measured data in 25 cities and the data of days with sunshine hours greater than 6 in 29 years are averaged as shown in Table 2. The top three are Mangya 346 days, Delingha 324.3 days, and Tuotuohe 317.7 days. The least is Guiyang 110.6 days. Among the 25 cities surveyed, 6 cities have more than 310 days, accounting for 24\% of the total. There are 8 cities between 250 310 days accounting 32\%; and 200 to 250 days for 4 cities, accounting for 16\%; there are seven cities with less than 200 days, accounting for $28 \%$. 
Table 2 Index statistics of solar energy resource assessment at different cities

\begin{tabular}{|l|l|l|l|l|l|l|l|l|}
\hline \multirow{3}{*}{ Places } & \multicolumn{2}{l}{ Rich degree } & \multicolumn{2}{l}{ Utilization value } & \multicolumn{2}{l}{ Stability degree } & \multicolumn{2}{l|}{$\begin{array}{l}\text { Average effective } \\
\text { sunshine duration }\end{array}$} \\
\cline { 2 - 10 } & $\begin{array}{l}\text { data } \\
\left(\mathrm{kWh} / \mathrm{m}^{2}\right)\end{array}$ & sort & data & sort & data & sort & data & sort \\
\hline Kuqa & 1590.077 & 12 & 280.2 & 11 & 2.37 & 12 & 0.619 & 14 \\
\hline Bugt & 1349.023 & 23 & 300.9 & 9 & 1.51 & 5 & 0.822 & 2 \\
\hline Mangnai & 1783.146 & 1 & 346 & 1 & 1.21 & 1 & 0.861 & 1 \\
\hline Delingha & 1701.517 & 3 & 324.3 & 2 & 1.37 & 2 & 0.819 & 3 \\
\hline Pagri & 1740.845 & 2 & 305.8 & 7 & 1.9 & 11 & 0.778 & 8 \\
\hline Tuotuohe & 1679.873 & 5 & 317.7 & 3 & 1.43 & 3 & 0.817 & 5 \\
\hline Wudu & 1450.577 & 18 & 206.7 & 18 & 2.67 & 14 & 0.589 & 18 \\
\hline Garze & 1655.266 & 6 & 297.5 & 10 & 1.59 & 8 & 0.778 & 9 \\
\hline Batang & 1681.158 & 4 & 313.1 & 5 & 1.49 & 4 & 0.818 & 4 \\
\hline Nyingchi & 1506.145 & 14 & 219 & 16 & 2.47 & 13 & 0.605 & 16 \\
\hline Huili & 1620.628 & 9 & 252.6 & 14 & 2.72 & 16 & 0.663 & 12 \\
\hline Baoji & 1499.01 & 15 & 211.9 & 17 & 2.68 & 15 & 0.593 & 17 \\
\hline Ankang & 1415.706 & 21 & 158.1 & 23 & 5.37 & 22 & 0.48 & 23 \\
\hline Guiyang & 1272.372 & 25 & 110.6 & 25 & 10.54 & 24 & 0.326 & 25 \\
\hline Yining & 1513.031 & 13 & 266.4 & 12 & 2.85 & 17 & 0.607 & 15 \\
\hline Turpan & 1598.976 & 11 & 314.2 & 4 & 1.87 & 10 & 0.758 & 10 \\
\hline Yumenzhen & 1645.451 & 7 & 311 & 6 & 1.57 & 7 & 0.801 & 6 \\
\hline Dalian & 1439.948 & 19 & 255.1 & 13 & 1.77 & 9 & 0.741 & 11 \\
\hline Madoi & 1624.339 & 8 & 302 & 8 & 1.56 & 6 & 0.783 & 7 \\
\hline Kunming & 1607.437 & 10 & 241 & 15 & 3.12 & 18 & 0.638 & 13 \\
\hline Wuhan & 1494.754 & 16 & 174.5 & 19 & 3.97 & 20 & 0.539 & 19 \\
\hline Chongqing & 1302.301 & 24 & 110.9 & 24 & 13.43 & 25 & 0.328 & 24 \\
\hline Hefei & 1451.862 & 17 & 172.9 & 20 & 3.43 & 19 & 0.536 & 20 \\
\hline Hangzhou & 1395.741 & 22 & 168.4 & 22 & 3.99 & 21 & 0.517 & 21 \\
\hline Nanchang & 1422.346 & 20 & 168.7 & 21 & 7.66 & 23 & 0.514 & 22 \\
\hline
\end{tabular}

\subsection{Stability degree}

The ration of maximum and minimum number of days with sunshine hours greater than 6 hours can indicate annual change of local solar energy resources, smaller the ratio, more stable the solar energy resources. Unstable solar energy resource is not unfavorable to utilitarian. It will significantly reduce the life of solar photovoltaic modules, and impact the battery conversion efficiency[14]. Therefore, the stability of solar energy resources is an important indicator of the assessment of solar energy resources. Stability degree is usually shown by k. The classification level is shown in table 3.

The ration of maximum and minimum days with sunshine time greater than 6 hours in 25 locations is averaged as shown in table 2. We can get that stability degree in the top three are Mangnai, Delingha and Tuotuohe. The least is Chongqing. Among the 25 cities surveyed, there are eleven cities that are very stable in solar energy resources, accounting for $44 \%$ of the total. There are ten cities that are stable in solar energy resource, accounting for $40 \%$. And there are four cities that are very unstable in solar energy resource, accounting for $16 \%$.

Table 3 Degree grade of stable about solar energy resource

\begin{tabular}{|l|l|}
\hline standard & Stability degree \\
\hline $\mathrm{k}<2$ & Very stable \\
\hline $2 \leq \mathrm{k} \leq 4$ & Stable \\
\hline $\mathrm{k}>4$ & Very unstable \\
\hline
\end{tabular}

\subsection{Average effective sunshine duration}

There are many factors that affect the solar radiation, and the most direct one is the local cloud cover and atmospheric transmittance, and the second is local terrain. Therefore, calculating the various parameters in the engineering design with local solar radiation will provide relatively large. So we need to use climatology and statistical methods from the solar radiation data to find the most 
representative values. After years of research and analysis, many scholars sum up regarding the local time 9 to 10 as the representative of the morning sunshine, and 11 to 13 as the representative of the sunshine at noon, and $14 \sim 15$ as the representative of the afternoon sunshine situation. The average of these three represents would be the effective sunshine hours for a region. Table 2 shows the average of the three periods in 29 cities for 25 cities.

The data is telling that the average effective sunshine hours in the top three are Mangya 0.861, Burke Figure 0.822, Delingha 0.819; the least average effective sunshine hours is Guiyang 0.326.

From Table 2, in determining a region of solar energy resources, we cannot be simply based on a certain indicator to determine. Such as Dalian, its richness is relatively low, but the stability is high; and Kunming richness is higher, but its stability is not high. Thus, it is not reliable to determine a region of solar energy resources is good or bad by only one indicator. Therefore, in the process of assessment, comprehensive consideration of these main indicators is really necessary, which requires the principal component analysis[15]. Principal component analysis method is to use less variables to explain more original variables, as a comprehensive index for data analysis and evaluation.

\section{Statistic and analysis}

Before analysis, it is necessary to acknowledge the analysis of the 25 cities' specific locations in China and distribution. As shown in Figure 1, the dots represent the location of each region. 25 cities are mainly distributed in the northwest, southwest, central China and east China, some individuals in the northeast. The difference of solar energy resources among these areas is large, and can reflect the situation of local solar energy resources.

\subsection{Overall assessment}

Four indexes of solar energy resources are analyzed by using the SPSS. In the main component analysis, because of the differences of measured units, it is necessary to standardize data, as shown in Table 4.

After the standardization, KMO and Bartlett's test are used to determine whether the data are reasonable for analysis by principal component analysis (PCA). And then correlation and commonality are going to be analyzed, after which we extract the principal component according to the variance. 
Table 4 Data Standardization of four indicators

\begin{tabular}{|l|l|l|l|l|}
\hline Places & $\begin{array}{l}\text { Rich } \\
\text { degree }\end{array}$ & Utilization value & Stability degree & $\begin{array}{l}\text { Average effective } \\
\text { sunshine duration }\end{array}$ \\
\hline Kuqa & 0.3788 & 0.49744 & -0.33769 & -0.22331 \\
\hline Bugt & -1.36326 & 0.79147 & -0.62478 & 1.1022 \\
\hline Mangnai & 1.77408 & 1.43209 & -0.72492 & 1.35685 \\
\hline Delingha & 1.18416 & 1.12385 & -0.67151 & 1.08261 \\
\hline Pagri & 1.46838 & 0.86107 & -0.49459 & 0.8149 \\
\hline Tuotuohe & 1.02774 & 1.0301 & -0.65148 & 1.06955 \\
\hline Wudu & -0.62934 & -0.54659 & -0.23755 & -0.4192 \\
\hline Garze & 0.84991 & 0.74318 & -0.59807 & 0.8149 \\
\hline Batang & 1.03703 & 0.96476 & -0.63145 & 1.07608 \\
\hline Nyingchi & -0.22776 & -0.37187 & -0.30431 & -0.31473 \\
\hline Huili & 0.59959 & 0.1054 & -0.22085 & 0.06399 \\
\hline Baoji & -0.27933 & -0.47272 & -0.23421 & -0.39308 \\
\hline Ankang & -0.88135 & -1.23692 & 0.66377 & -1.13093 \\
\hline Guiyang & -1.9172 & -1.91163 & 2.38961 & -2.13649 \\
\hline Yining & -0.178 & 0.30142 & -0.17746 & -0.30167 \\
\hline Turpan & 0.44311 & 0.98039 & -0.504 & 0.6843 \\
\hline Yumenzhen & 0.77898 & 0.93494 & -0.60475 & 0.96508 \\
\hline Dalian & -0.70616 & 0.14091 & -0.53798 & 0.5733 \\
\hline Madoi & 0.62641 & 0.8071 & -0.60809 & 0.84754 \\
\hline Kunming & 0.50426 & -0.05937 & -0.08733 & -0.09925 \\
\hline Wuhan & -0.31008 & -1.00397 & 0.19642 & -0.74568 \\
\hline Chongqing & -1.73391 & -1.90737 & 3.35435 & -2.12343 \\
\hline Hefei & -0.62006 & -1.0267 & 0.01616 & -0.76527 \\
\hline Hangzhou & -1.02564 & -1.09062 & 0.2031 & -0.88933 \\
\hline Nanchang & -0.83337 & -1.08635 & 1.42821 & -0.90892 \\
\hline & & & & \\
\hline
\end{tabular}

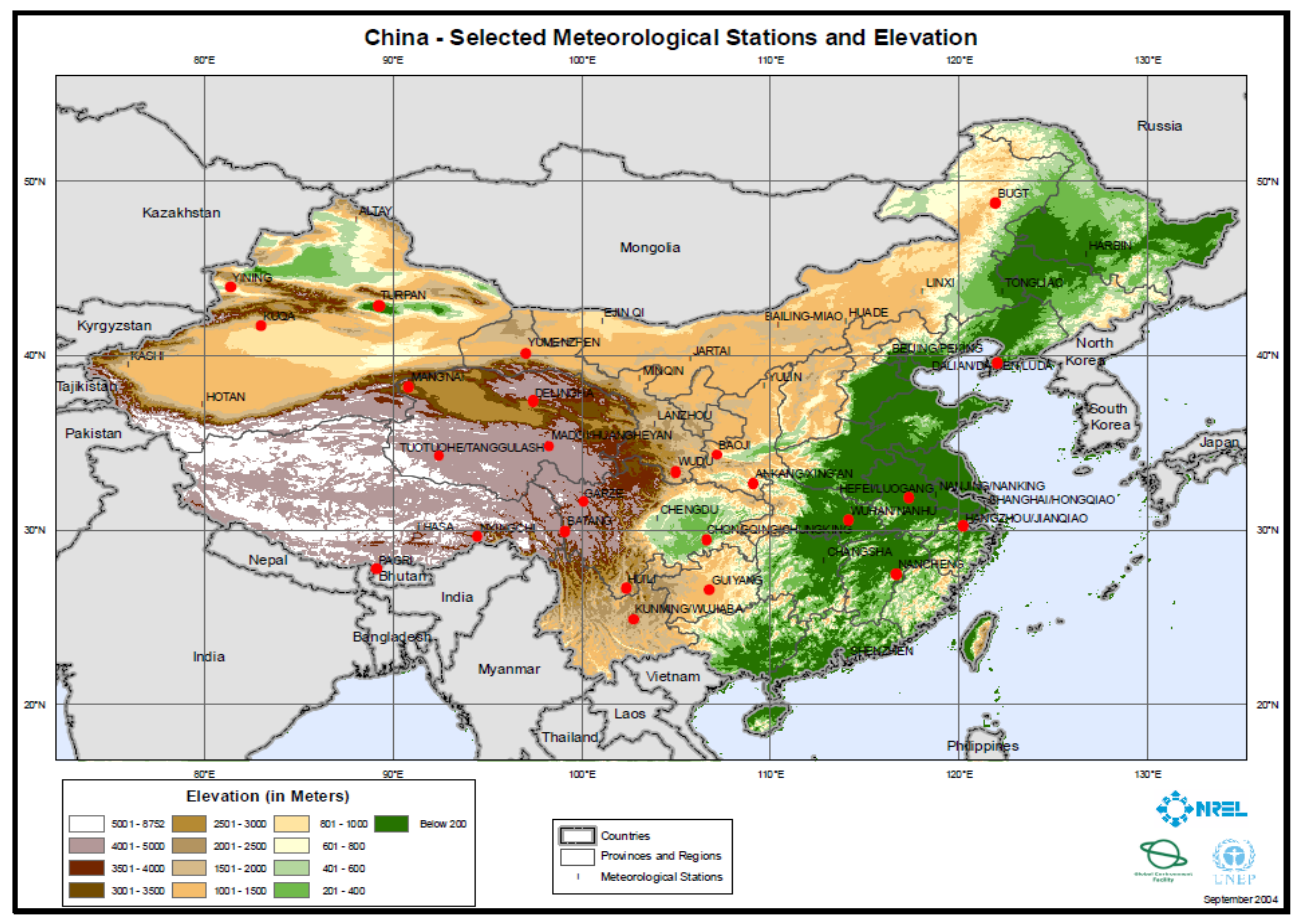

Fig. 1 Location and distribution of 25 locations 


\subsubsection{Analysis of correlation}

Table 5 Correlation analysis of different indicators

\begin{tabular}{|l|l|l|l|l|}
\hline & $\begin{array}{l}\text { Rich } \\
\text { degree }\end{array}$ & $\begin{array}{l}\text { Utilization } \\
\text { value }\end{array}$ & $\begin{array}{l}\text { Stability } \\
\text { degree }\end{array}$ & $\begin{array}{l}\text { Average effective } \\
\text { sunshine duration }\end{array}$ \\
\hline Rich degree & 1.000 & 0.835 & -0.704 & 0.791 \\
\hline Utilization value & 0.835 & 1.000 & -0.822 & 0.966 \\
\hline Stability degree & -0.704 & -0.822 & 1.000 & -0.859 \\
\hline $\begin{array}{l}\text { Average effective sunshine } \\
\text { duration }\end{array}$ & 0.791 & 0.966 & -0.859 & 1.000 \\
\hline
\end{tabular}

We can see from the table 5 , utilization value and average effective sunshine duration have a higher correlation. The value is 0.966 .

3.1.2 KMO and Bartlett's Test.

$\mathrm{KMO}$ value is used to check whether the data is reasonable for PCA or not. If it is between 0.5 and 1.0, then we say it is reasonable, but if less than 0.5, not suitable. Bartlett test of spherome is done through being converted into $\chi^{2}$ test to examine whether variables are independent. If the value is larger, we can use PCA.

Table 6 KMO and Bartlett's Test

\begin{tabular}{|l|l|l|}
\hline \multicolumn{2}{|l|}{ Kaiser-Meyer-Olkin Measure of Sampling Adequacy. } & 0.778 \\
\hline Bartlett's Test of Sphericity & Approx. Chi-Square & 115.069 \\
\cline { 2 - 3 } & Df & 6 \\
\cline { 2 - 3 } & Sig. & 0.000 \\
\hline
\end{tabular}

The KMO value is 0.778 , between 0.5 and 1.0. The asymptotic value of $\chi^{2}$ is 115.069 , and significant probability (Sig) is less than 0.001 , which means significance is high. Therefore, we can use PCA.

3.1.3 Variance explained.

Common factor variance can measure the relative importance of common factors. Extract common factors that eigenvalues greater than 1. Calculated this eigenvalue is 3.493, and the cumulative contribution rate is 87.336. So extract a main component, as we can see in table 7 .

Table 7. Total variance explained

\begin{tabular}{|l|l|l|l|}
\hline \multirow{2}{*}{ Component } & \multicolumn{4}{|l|}{ Initial Eigenvalues } \\
\cline { 2 - 4 } & Total & \% of Variance & Cumulative \% \\
\hline 1 & 3.493 & 87.336 & 87.336 \\
\hline 2 & 0.305 & 7.633 & 94.969 \\
\hline 3 & 0.173 & 4.336 & 99.305 \\
\hline 4 & 0.028 & 0.695 & 100.000 \\
\hline & \multicolumn{4}{|l|}{ Extraction Sums of Squared Loadings } \\
\hline Component & \multicolumn{4}{|l}{ Total } & \% of Variance & Cumulative \% \\
\hline 1 & 3.493 & 87.336 & 87.336 \\
\hline
\end{tabular}

3.1.4 Communality.

Communality refers to a test item in all factors to the factor loading on the quadratic sum. It represents all factors combined to explain that entry variation. As we all know, factor is a simplification, it is used to replace many of the entries. Thus, if there are two entries have highly Communalities, represents a high coincidence degree information which provided by these two entries. On the contrary, it means that their information is not coincident.

In the table 8 we can get that utilization value and average effective sunshine duration have highly communalities, their value are 0.944 and 0.941 respectively. 
Table 8. Communality of variable

\begin{tabular}{|l|l|l|}
\hline & Initial & Extraction \\
\hline Rich degree & 1.000 & 0.789 \\
\hline Utilization value & 1.000 & 0.944 \\
\hline Stability degree & 1.000 & 0.819 \\
\hline Average effective sunshine hours & 1.000 & 0.941 \\
\hline \multicolumn{2}{|l|}{ Extraction Method: Principal Component Analysis. } \\
\hline
\end{tabular}

\subsubsection{Principal component scores.}

First, the common factor with feature value greater than 1 is extracted according to the variance. As shown in Table 7, the eigenvalue is 3.493 and the cumulative contribution rate is 87.336, so a principal component is extracted. Then by factor score matrix (Table 9), we could have the principal component score function, as shown in equation (1).

Table 9. Component score coefficient matrix

\begin{tabular}{|l|l|}
\hline & Component \\
\cline { 2 - 2 } & 1 \\
\hline Rich degree & 0.254 \\
\hline Utilization value & 0.278 \\
\hline Stability degree & -0.259 \\
\hline Average effective sunshine hours & 0.278 \\
\hline $\begin{array}{l}\text { Extraction Method: Principal Component Analysis. } \\
\text { Rotation Method: Varimax with Kaiser Normalization. } \\
\text { Component Scores. }\end{array}$ \\
\hline
\end{tabular}

$$
\mathrm{F}=0.254 \mathrm{X}_{1}+0.278 \mathrm{X}_{2}-0.259 \mathrm{X}_{3}+0.278 \mathrm{X}_{4}
$$

In equation (1), $X_{1}$ is the degree of abundance, $X_{2}$ the use value, $X_{3}$ the degree of stability, and $\mathrm{X}_{4}$ the average effective utilization hours. It should be noted that the values of $\mathrm{X}_{1-4}$ are normalized. This equation represents a quantitative description of the overall assessment of solar energy resources.

\subsection{Analysis and Discussion}

Table 5 and Table 8 show that the utilization value and the average effective utilization hours have high commonality and correlation. Therefore, one of them can be used together with other two parameters to assess the solar energy resources. In order to obtain which parameters can be used to provide more comprehensive information, these parameters are re-combined and calculated. To facilitate a better description, we will rename and recombine them. The combination of these four indicators is called the overall assessment. The richness, the use of value and stability are called combination 1 , and the rich degree, stability and the average effective utilization are called combination 2.

We repeat the above steps in 3.1 for those two combinations, and get their own principal component score functions, as shown in equation (2) (3) below. According to the principal component scoring function, the principal component scores are calculated separately for the three groups of data, such as overall assessment, combination 1 and combination 2, and then the comparison happens.

$$
\begin{gathered}
F=0.355 X_{1}+0.372 X_{2}-0.353 X_{3} \\
F=0.348 X_{1}-0.36 X_{3}+0.372 X_{4}
\end{gathered}
$$

Figure 2 is telling us that the result, obtained from the overall assessment, combination 1 , and combination 2, is that 15cities in the same rank; in different ranks, the different value between the highest and lowest one of the three combinations is from 1 to 4 (1 for 4 locations, 2 for 4 locations, 3 for one location and 4 for one location). The results of the three combinations are basically the same. It is sufficient to show that the information provided by the two evaluation indices, utilization value and average effective hours, are similar. Therefore, in the future, we can omit one indicator and change the original four evaluation indicators into three. That is, we can just use the richness, 
the utilitarian of value and stability, or richness, stability and average effective hours of sunshine, to assess.

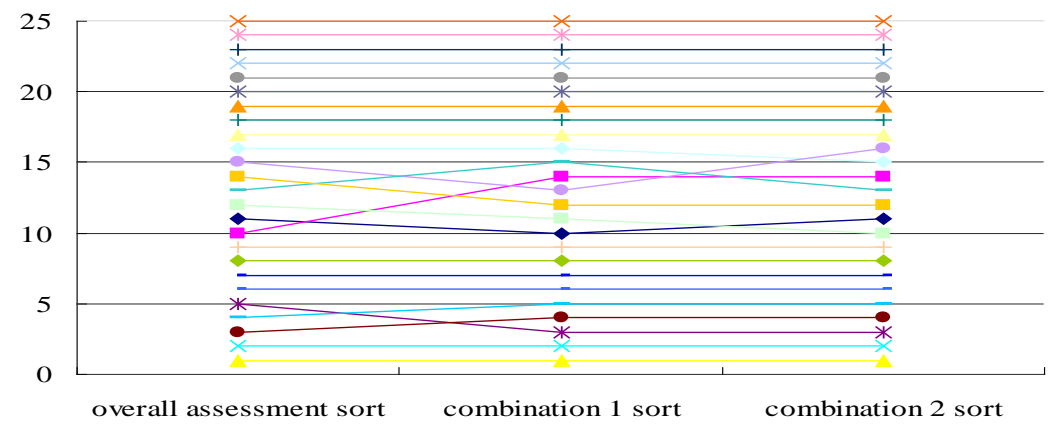

Fig. 2 Sort of principal component score

Through careful analysis, we can be obtained that the higher score of a principal component the indicating that richness, use value or stability is better. In order to better determine the solar energy resource situation in a certain area, the solar energy resource is divided into five grades according to the score of principal component, as shown in Table 10.

Table 10. Grade of solar resources

\begin{tabular}{|l|l|}
\hline Principal component scores & Solar energy resources \\
\hline$>1$ & Very good \\
\hline $0.6 \sim 1$ & Good \\
\hline $0.3 \sim 0.6$ & General \\
\hline $0 \sim 0.3$ & Poor \\
\hline$<0$ & Very poor \\
\hline
\end{tabular}

\section{Conclusion}

(1) Using the method of principal component analysis in mathematical statistics, the comprehensive evaluation results of the four evaluation indexes of solar energy resources assessment can be obtained. This method can evaluate the solar energy resources in a certain area more comprehensively.

(2) By calculating, the commonality and the correlation between the utilitarian value and the average effective hours of sunshine are relatively high. This was verified by calculate the component score of the three groups of data such as overall assessment, combination 1 and combination 2.

(3) Through reducing the four evaluation indexes to three, the result of reduction is almost the same as before. It is proved that it is feasible to evaluate solar energy by using three indexes, such as abundance degree, utilitarian value and stability degree, or the three indexes of abundance degree, stability degree and average effective sunshine hour to evaluate solar energy.

(4) Using the principal components of a region to determine the solar energy resources in the region, solar energy resources are divided into five grades, namely, very good, good, general, poor and very poor. Among them, the places in which the main component score is greater than 1 for the solar energy resources are very good areas, and so on, and the main component score is less than 0 for solar energy resources are very poor areas.

\section{Acknowledgment}

Corresponding author: Mingzhi Zhao (1976-), Associate Professor.

E-mail: zhaomingzhi2020@163.com

Project funds: Natural Science Foundation of China (51466011)

Natural Science Foundation of Inner Mongolia (2014MS0511) 


\section{References}

[1] Han Shitao, Liu Yulan, Liu Juan, Evaluation analysis on solar energy resources in Ningxia, Journal of Arid Land Resources and Environment , 2010,24(08):131-135.

[2] Yuan Xiaokang, Gu Xiaoping, Wang Ji, Research Progress of Solar Energy Resources Evaluation in China, Journal of Guizhou Meteorology, 2011, 35(05):1-4.

[3] Zhu Biao, Li Chunhua, Fang Feng, Solar Energy Resource Assessment in Gansu Province , Journal of Arid Meteorology , 2010, 28(2):217-221.

[4] Liang Junxia, Li Xu, Zhu Honglu, Kang Nan, Qi Cheng, Yao Jianxi. Solar Resource Analytical Method of Diurnal Variation for Photovoltaic Power Generation, Water Resources and Power , 2015 , 33(3):205-208.

[5] Mondal MAH, Denich M. Assessment of renewable energy resources potential for electricity generation in Bangladesh , Renewable and Sustainable Energy Reviews, 2010, 14(8):24012413.

[6] H.Broesamle, H.Mannstein, C.Schillings, F. T. Assessment of solar electricity potential sin north Africa base Don satellite data and A geographic information system , Solar Energy , 2001, 70(1):1-12.

[7] Ko L, Wang J-C, Chen C-Y, Tsai H-Y. Evaluation of the development potential of rooftop solar photovoltaic in Taiwan, Renewable Energy. 201576:582-595.

[8] Nandi SK, Hoque MN, Ghosh HR, Chowdhury R. Assessment of Wind and Solar Energy Resources in Bangladesh, Arabian Journal for Science and Engineering, 2012, 38(11):31133123.

[9] Yuan Shujie, Li Xiaohong, Zhang Yiwei, Li Dejiang, Zhang Wenzong. Study on temporal and spatial distribution of horizontal global solar radiation and evaluation of solar energy resources in Hebei Province, Journal of Northeast Agricultural University, 2013, 44(11):50-55.

[10] Zhang Hongwei. A Solar Energy Resources Assessment in Dongying, Lanzhou University, Lanzhou, 2014

[11] Zhou Yang, Wu Wenxiang, Hu Ying, Liu Guangxu. The Temporal-spatial Distribution and Evaluation of Potential Solar Energy Resources in Northwest China , Journal of Natural Resources, 2010,25(10):1738-1749.

[12] Assessment Method for Solar Energy. Meteorological industry standard of the People's Republic of China; QX/T89-2008.

[13] Zhou Yang, Wu Wenxiang, Fang Qian, Liu Guangxu. The assessment of available solar energy resources potential in Jiangsu Province, Renewable Energy Resource,2010, 28(06):1013.

[14] Zhao Yuan, Zhao Hui. Resource and Utilization of Solar Energy in China, Economic geography, 1998, 18(1):56-61.

[15] Yu Xiulin, Ren Xuesong. Multivariate statistical analysis China statistics press, Beijing.1998, 7:154-170. 